\title{
O sim e o não em pareceres de revista acadêmica - estudo das metafórass interpessoais sob a perspectiva sistêmico-funcional
}

\author{
Osilene Maria de Sá e Silva da Cruz*
}

\begin{abstract}
RESUMO
Estudos revelam a importância de análises discursivas em textos acadêmicos, tendo em vista os temas tratados nas pesquisas e as instanciações presentes nesse gênero. Esta pesquisa analisa pareceres de artigos de uma revista científica de Linguística (RL1), tendo como embasamento teórico a perspectiva da Linguística Sistêmico-Funcional (HALLIDAY, 1994; HALLIDAY e MATTHIESSEN, 2004), sobretudo a metafunção interpessoal e o conceito de metáfora gramatical. O corpus é constituído por 67 pareceres de artigos, organizados em três grupos: aprovados sem restrições (A), aprovados com restrições (AR) e reprovados (R). A investigação, de cunho qualitativo, identificou treze tópicos (aboutness) abordados pelos pareceristas: Análise, Argumentação, Bibliografia, Contribuição, Forma, Língua, Metodologia, Objetivo, Resultado, Resumo, Tema, Teoria e Título, que foram analisados na perspectiva da metáfora interpessoal, com avaliações predominantemente positivas no grupo de pareceres A e negativas nos grupos de pareceres AR e R. Os pareceristas indicaram correções e sugestões de mudanças no grupo de pareceres A, sendo as instanciações realizadas por metáfora interpessoal, como estratégia dos pareceristas de suavizar a crítica. O grupo de pareceres AR apresenta metáforas interpessoais, sobretudo quando se sinalizam sugestões para correções. $\mathrm{O}$ grupo de pareceres $\mathrm{R}$ apresenta críticas negativas, principalmente, por meio de enunciados monoglóssicos, impedindo ou dificultando negociação entre o autor do artigo e o parecerista. Os resultados desta pesquisa trazem contribuições para estudos sobre metáfora gramatical e sobre o gênero parecer de revista científica, contribuindo, também, com a revista RL1, trazendo-lhe subsídios para melhorar ainda mais sua qualidade e prestígio.
\end{abstract}

Palavras-chave: Linguística Sistêmico-Funcional. Metáfora Gramatical. Metáfora Interpessoal. Pareceres. Escrita acadêmica.

1 Instituto Nacional de Educação de Surdos - INES. Professora Adjunta do Departamento de Ensino Superior - DESU, onde ministra a disciplina de Língua Portuguesa como L2. Interesse por pesquisas na área de ensino de Língua Portuguesa como L2, escrita acadêmica, com enfoque para as abordagens da Linguística Sistêmico-Funcional e da Avaliatividade. 


\section{Introdução}

"Publique ou pereça". A célebre citação, cuja autoria é atribuída a diversas fontes, faz parte de uma cultura cada vez mais arraigada na comunidade científica nacional e internacional. Apesar de não se ter conhecimento exato acerca de sua primeira menção, sabe-se que traduz significados ambivalentes: por um lado, denota significado pejorativo, sinalizando uma constante pressão por parte da academia para que cientistas e pesquisadores publiquem incessantemente. Schlendlindwein (2009) denomina esse fenômeno de "fordismo científico", uma vez que artigos científicos são produzidos em massa, como em uma "linha de montagem", na qual estão inseridos "do estudante de iniciação científica ao pós-doc, todos juntando partes para o mesmo resultado final: o artigo científico" (SCHLENDLINDWEIN, 2009 , p. 10). Segundo o autor, a lógica da produtividade passa a ser a lógica da repetição, e não a da criação, da novidade. O resultado, de acordo com o autor, é a existência crescente de cientistas e decrescente de Ciência.

Por outro lado, a citação remete o leitor ou ouvinte a um aspecto positivo, no que se refere ao crescimento das publicações científicas, que têm sido cada vez mais recorrentes no meio acadêmico, possibilitando a divulgação do conhecimento dentro de comunidades discursivas específicas, constituídas por pesquisadores novatos e especialistas. Gruszynski, Golin e Castedo (2008, p. 3) confirmam a informação de Houghton (1975), segundo o qual, os primeiros periódicos científicos - Journal des Sçavans e Philosophical Transaction -, publicados em 1665, contribuíram como modelos diferentes para a literatura científica: o primeiro influenciou o desenvolvimento das revistas dedicadas à ciência geral, sem comprometimento com uma área de conhecimento específica; o segundo tornou-se modelo das publicações das sociedades científicas, que apareceram em grande número na Europa durante o século XVIII.

Ao discutir sobre divulgação científica, Volpato e Freitas (2003, p. 50) mostram que, apesar de a divulgação informal da ciência, via congressos, palestras, visitas, dentre outros meios, permitir uma rápida veiculação da informação, a divulgação formal (publicação impressa ou online) ainda é a maior responsável por oferecer credibilidade suficiente para que a informação seja aceita como referência para outros trabalhos. Nessa perspectiva, a publicação pode ser considerada, então, um ato social, devido à contribuição para a divulgação do conhecimento, sendo que, ao buscá-lo, pesquisadores acessam diversos meios de divulgação (periódicos, livros, 
revistas, teses e dissertações) para obter mais informação acerca de determinado tema. Isso corrobora o pressuposto de Estrela (2001, p.3) ao ressaltar que a leitura de textos científicos é um dos métodos mais recorrentes para a obtenção do conhecimento.

Diante da busca pelo trabalho científico escrito e de sua importância, é imprescindível considerar o processo de avaliação pelo qual ele passa antes da publicação, feito por avaliadores especialistas na área de conhecimento do referido trabalho. Essa avaliação, tradicionalmente denominada parecer, definida como "uma opinião de um especialista em resposta a uma consulta" (HOUAISS e VILLAR, 2001, p. 2.133), possibilita a legitimação do trabalho acadêmico e a veiculação do conhecimento de forma confiável. Sob esse ponto de vista, o parecer tem grande importância na academia porque apresenta o aval do parecerista acerca de determinado trabalho, trazendo críticas positivas e/ou negativas referentes a componentes de um artigo acadêmico, seja à parte formal (estrutura do trabalho e linguagem), à parte conceitual (teoria(s) envolvida(s) na pesquisa) e/ou à parte metodológica (procedimentos realizados na pesquisa).

Tendo em vista a importância da publicação científica no mundo atual, que possibilita a divulgação de trabalhos de qualidade e referência, a presente pesquisa tem como objetivo analisar a avaliação presente no gênero parecer de artigos submetidos para publicação a uma revista científica da área de conhecimento de Linguística. Especificamente, busca-se identificar e analisar a presença de metáforas gramaticais / interpessoais nos artigos, em uma perspectiva sistêmicofuncional, a partir do posicionamento do parecerista ao elaborar a avaliação.

É consenso que a avaliação de trabalhos acadêmicos busca ser imparcial, embora se tenha conhecimento de que a imparcialidade e impessoalidade não impedem o envolvimento do avaliador ou parecerista com o texto produzido. A avaliação revela-se por marcas de subjetividade (de forma consciente ou não), por elementos modais ("pode", "poderia", "deve", "deveria”) ou lexicais (epíteto, elementos circunstanciais, processos), perguntas retóricas, elementos de negação, metáfora gramatical, dentre outros. Assim, essa observância de elementos avaliativos em pareceres, aliada ao interesse de estudar a avaliação em artigos acadêmicos na área da Linguística, contribuíram para a idealização deste trabalho.

$O$ interesse por gêneros acadêmicos pode ser encontrado em vários estudos realizados na literatura, dentre eles Machado (2002), que se debruça sobre o gênero resumo; Motta-Roth (2002), que se volta para resenhas acadêmicas em 
diferentes áreas de conhecimento; Pilar (2002), que estuda o gênero redações de vestibular; Bernardino (2007), que investiga o metadiscurso interpessoal em artigos acadêmicos; Lins (2007), que discorre sobre o ensino dos gêneros discursivos no ensino de língua materna; Paula (2009), que trabalha com o metadiscurso interpessoal e textual em introduções de artigos científicos; Vian Jr. e Ikeda (2009), que se dedicam a estudar o gênero resenha acadêmica na formação de professores; Vivan (2010), que analisa processos verbais e metáforas interpessoais em artigos acadêmicos; Bárbara e Macedo (2011), com o estudo sobre processos verbais em artigos científicos e diversas áreas de conhecimento; Moraes (2011), com estudo comparativo da seção "Conclusão" em artigos científicos de Linguística e Odontologia, dentre outros. Assim como ocorre nesta pesquisa, alguns dos trabalhos citados estão inseridos no escopo da Linguística Sistêmico-Funcional (doravante LSF) e envolvem análise e descrição do discurso acadêmico na grande área da Linguística Aplicada, no sentido de mostrar as intenções de um parecerista ao elaborar o parecer relativo a um trabalho submetido à decisão editorial. Entretanto, nenhum deles refere-se à análise de pareceres de artigos submetidos a alguma revista científica, fator que também faz parte do rol de justificativas para a realização da presente pesquisa.

Portanto, o foco deste artigo, recorte de uma pesquisa mais ampla, concentra-se na análise de pareceres, mais especificamente, na análise dos posicionamentos dos avaliadores, partindo-se do pressuposto de que os pareceristas apresentam maior grau de polidez ao apresentarem suas restrições ou indicações de mudança nos artigos submetidos para avaliação. Para isso, o trabalho está divido em 4 seções, além da Introdução e das Referências.

A seguir, apresento questões teóricas sobre a Linguística Sistêmico-Funcional, com destaque para a metafunção interpessoal, a partir dos pressupostos de Halliday (1994) e Halliday e Mathiessen (2004).

\section{A Linguística Sistêmico-Funcional e a metafunção interpessoal}

A LSF representa uma opção para os pesquisadores interessados nos aspectos semânticos do discurso e no estudo da influência do contexto de cultura sobre o contexto de situação e vice-versa. Diferentemente de outras abordagens, a LSF preocupa-se com o significado e o funcionamento da língua, ou seja, com a língua em uso e seus aspectos semânticos e funcionais. 
De acordo com Halliday e Mathiessen (2004, p. 29), a linguagem constrói a experiência humana porque é capaz de nomear as coisas e de explicitar a experiência humana e as relações pessoais e sociais. Assim, as orações são formas de representação e de troca de relações, consideradas por meio das metafunções ideacional, interpessoal e textual.

Analisando o enunciado "Ela comprou os livros para mim mês passado", podemos desenvolver a compreensão a partir de três significados: o do campo ideacional, da realização, composto pelos participantes da ação (quem faz o quê para quem); o do campo interpessoal, constituído pelas relações entre esses participantes, tendo em vista a modalidade no enunciado, relacionada, por exemplo, à certeza ou frequência do enunciado e ao tempo da ação; e o do campo textual, de organização da informação (informação dada e informação nova). No exemplo citado, os participantes identificam-se como "Ela" e "para mim", e ainda podemos identificar a circunstância em que o processo comprar ocorre: "no mês passado". A metafunção interpessoal é representada pelo processo no tempo passado, indicando certeza da ação. A metafunção textual, por sua vez, é instanciada por tema (Ela) e rema (comprou os livros para mim mês passado), em que a informação dada é "ela" e a informação nova é o restante da oração.

Tendo em vista a importância do significado em um conjunto de instanciações e de sua relação com o contexto: de situação (imediato, léxico-gramatical) e de cultura (amplo, cultural), o construto teórico proposto pela LSF é um dos que contempla o que se propõe estudar nesta pesquisa, porque oferece subsídios para a análise léxicogramatical e semântica dos pareceres estudados, considerando-se o contexto de situação e o contexto de cultura no qual foram elaborados e circulam.

Para explicitar essas duas noções, Eggins (1994, p. 50) remonta aos estudos de Malinowski (1946, 1935), um dos pioneiros a considerar a linguagem como um fato social e que propôs a noção de context of culture, traduzida como contexto de cultura, que, como o próprio nome revela, considera os aspectos culturais envolvidos nas interações verbais. $\mathrm{O}$ antropólogo propôs também a noção de context of situation, traduzida como contexto de situação, que se refere ao ambiente no qual o texto está sendo realizado, incluindo o ambiente verbal e a situação de uso. Para ele, esses dois tipos de contexto são fundamentais para a compreensão de um texto.

Na próxima subseção, apresento a metafunção interpessoal, enfoque desta pesquisa, por ser a metafunção que materializa as instanciações de metáfora interpessoal. 


\subsection{A metafunção interpessoal e a metáfora gramatical de Halliday}

A metafunção interpessoal refere-se à interação entre os participantes do discurso $^{1}$, na qual o falante assume um papel de fala e demanda do seu ouvinte uma resposta. Halliday (1994, p. 68) indica que, ao proferir um enunciado, "o falante adota para si um papel particular no discurso e, dessa forma, atribui ao ouvinte um papel complementar que ele quer que este adote”. Ocorrem, então, situações comunicativas distintas, como um pedido, um convite, uma avaliação, uma rejeição, dentre outras, que são realizadas na interação entre os falantes ou uma troca, na qual dar implica receber e pedir implica dar. Nesse contexto, os interlocutores desempenham os principais papéis de fala: dar e pedir, nos quais estão incluídos todos os outros papéis (HALLYDAY, 1994, p. 68; HALLIDAY e MATHIESSEN, 2004, p. 107). Essa troca é natural e constante nas interações, uma vez que o falante ou oferece algo ao ouvinte (uma informação, por exemplo) ou pede algo ao ouvinte (HALLIDAY, 1994, p. 68). Nessa relação, ocorre uma troca ("commodity") de bens e serviços ou de informação, conforme indica o Quadro 1.

QUADRO 1: Relações nas interações (HALLIDAY e MATTHIESSEN, 2004, p. 107)

\begin{tabular}{|l|l|l|}
\hline \multirow{2}{*}{ Papel na troca } & \multicolumn{2}{|c|}{ Mercadoria trocada } \\
\cline { 2 - 3 } Dar & \multicolumn{1}{|c|}{$\begin{array}{l}\text { Bens e serviços } \\
\text { Oferta: Você gostaria de um } \\
\text { bule de chá? }\end{array}$} & $\begin{array}{l}\text { Declaração: Ele está dando a } \\
\text { ela o bule de chá. }\end{array}$ \\
\hline Pedir & $\begin{array}{l}\text { Comando: Dê-me aquele } \\
\text { bule de chá. }\end{array}$ & $\begin{array}{l}\text { Pergunta: O que ele está } \\
\text { dando a ela? }\end{array}$ \\
\hline
\end{tabular}

A ponte entre as opções modais subjacentes e as categorias lexicais é fornecida pela noção hallidayana de metáfora interpessoal (HALLIDAY, 1994). No modelo de Halliday, os valores modais podem ser realizados de forma congruente (não metafórica) através de auxiliares modais (pode, deve, poderia, etc) e adjuntos modais (talvez, possivelmente, certamente), e metaforicamente através de formulações mais lexicais como "É possível que...”, “É necessário que...”, “Eu

1 Discurso, na concepção funcionalista (HALLIDAY, 1978), consiste em um processo multidimensional, tendo o texto como seu produto. O discurso é entendido como uma troca de significados em contexto interpessoal. 
acho que...”, etc. É possível construir uma série de realizações de probabilidade (É provável que...), frequência (raramente, ...) e capacidade (Ele é capaz de...), começando de forma congruente (através de formulações 'gramaticais'), passando por formulações metafóricas (mais lexicalizadas), até chegar a um léxico de natureza claramente valorativa.

Berber Sardinha (2007), ao apresentar um mapeamento de estudos sobre metáfora, mostra os conceitos de várias correntes em ordem cronológica e destaca que metáforas fazem parte do dia a dia de qualquer língua, desde a infância até a idade mais avançada. $\mathrm{O}$ autor retoma três conceitos que contribuem para o estudo da metáfora: metáfora conceptual (LAKOFF e JOHNSON, 1980), metáfora sistemática (CAMERON, 2003) e metáfora gramatical (HALLIDAY, 1994).

Neste trabalho, será detalhada a noção de metáfora gramatical, porque, como já anunciado na Introdução e no início deste capítulo, ela servirá como suporte para a análise dos elementos avaliativos nos pareceres.

O termo metáfora gramatical é utilizado na LSF para indicar o tipo de significado diferente do significado congruente. $\mathrm{Na}$ perspectiva sistêmico-funcional, a metáfora localiza-se no estrato da Semântica do Discurso porque provoca uma interpretação que vai além do significado literal. Nas palavras de Halliday (1994), "metáfora é geralmente descrita como variação do uso das palavras: uma palavra é dita para ser usada com um sentido modificado [...] é a variação na expressão dos significados" (HALLIDAY, 1994, p. 341). Thompson (1996, p. 166) corrobora essa definição e assevera que as metáforas apresentam significados diferentes de fraseados congruentes, não sendo nem melhores nem piores do que eles. Para Halliday (1994, p. 350), o significado congruente é veiculado utilizando-se palavras mais simples, mais próximas de seus significados. Os exemplos extraídos de Halliday (1994) mostram a diferença entre os significados congruente e metafórico, conforme Quadro 2.

QUADRO 2: Significados congruente e metafórico (HALLIDAY, 1994, p. 346).

\begin{tabular}{|l|l|}
\hline Significado congruente & Eles chegaram ao topo no quinto dia. \\
\hline Significado metafórico & O quinto dia os viu chegar ao topo. \\
\hline
\end{tabular}

O enunciado "Eles chegaram ao topo no quinto dia" seria a forma congruente de 
"O quinto dia os viu chegar ao topo", porque a construção metafórica representada pela circunstância de tempo (“o quinto dia”) é estruturada como participante do processo mental "ver”. Para Halliday (1994, p. 342), então, o uso da palavra congruente no lugar da metafórica implica o reconhecimento do termo congruente, pois o reconhecimento de palavras congruentes possibilita o reconhecimento de outras possibilidades de usar as palavras. Hallliday acrescenta que a opção pelo uso da metáfora é uma escolha cheia de significados, pois envolve uma seleção dentro de uma gama de outros significados disponíveis no sistema linguístico.

$\mathrm{Na}$ perspectiva sistêmica, a metáfora gramatical é abordada sob duas perspectivas: metáfora ideacional (ou metáfora de transitividade) e metáfora interpessoal (ou metáfora de modo), sendo esta última utilizada nesta pesquisa para avaliar o posicionamento do parecerista.

A metáfora interpessoal denota mudança na função das orações, pois uma oração declarativa passa a ter sentido interrogativo ou de comando, uma oração interrogativa passa a ter sentido de comando e uma oração de sentido de comando passa a ter sentido de pergunta. Halliday (1994, p. 365) destaca que o enunciado "Se eu fosse você, eu não..." é a forma metafórica de "Não...", funcionando como um aviso, conselho. O mesmo ocorre com a construção "Seria melhor que ela [...]", que é a forma metafórica de "Ela deveria...", também funcionando como um aviso. Em ambos os casos, o significado da proposição é atenuado.

Referindo-se ao significado transmitido em uma interação em que ocorre modalidade 2 , Halliday e Mathiessen (2004, p. 631) destacam que o potencial criado pelas metáforas de modo em um diálogo está diretamente relacionado com as variáveis contextuais de relações no discurso e que podem denunciar formas de status, formalidade e polidez.

Na próxima seção, descrevo o corpus e apresento a sua organização.

\section{Procedimentos metodológicos}

Nesta pesquisa, opta-se pela abordagem de pesquisa qualitativa (Chizzoti, 1998; Flick, 2009), devido ao foco principal: análise de conteúdo, mais especificamente, análise dos discursos referentes às avaliações e aos posicionamentos dos pareceristas no corpus de estudo, com o objetivo de identificar as instanciações

2 De acordo com Halliday (1994, p. 356), modalidade se refere aos discursos de probabilidade e frequência (modalização) e obrigação e inclinação (modulação). 
metafóricas interpessoais dos avaliadores nos grupos de pareceres Aprovados (A), Aprovados com Restrições (AR) e Reprovados (R).

Os dados foram interpretados $\mathrm{e}$ discutidos, proporcionando a identificação e a descrição das características da linguagem utilizada no contexto de produção, assim como o fornecimento de exemplos/ocorrências dos respectivos posicionamentos nos pareceres.

\subsection{Descrição e organização do corpus}

O corpus da pesquisa é constituído por 67 pareceres $^{3}$ referentes a artigos submetidos a uma revista da área de conhecimento de Linguística (doravante RL1), cujos pareceres são escritos em língua portuguesa do Brasil, elaborados entre 2004 a $2010^{4}$. Os pareceres foram separados da seguinte forma:

- 12 pareceres aprovados sem restrições (A): de 01 a 12 - A01, A02, A03, A04 até A12;

- 35 pareceres aprovados com restrições (AR): de 01 a 35 - AR01, AR02, AR03, AR04 até AR35;

- 20 pareceres reprovados (R): de 01 a 20 - R01, R02, R03, R04 até R20.

Como exemplo: A02 refere-se ao parecer número 02, de um artigo aprovado sem restrições (A02). As abreviações AR e R referem-se, respectivamente, a pareceres de artigos aprovados com restrições e reprovados.

Após a leitura detalhada dos pareceres, verificou-se que as justificativas dos pareceristas abordavam assuntos específicos ou tópicos, os quais foram classificados em: análise (AN), argumentação (AR), bibliografia (BI), contribuição $(C O)$, forma (FO), língua (LIN), metodologia (MET), objetivo (OB), resultado (RET), resumo/abstract (RES), teoria (TE), tema (TM), titulo (TI).

Na próxima seção, será apresentada a Análise dos dados e a discussão dos resultados obtidos.

3 Esta pesquisa foi autorizada pela editoria da RL1 e passou pelo Comitê de Ética da Instituição em que foi realizada a pesquisa mais ampla. Houve um entendimento entre a pesquisadora e a Revista no sentido de resguardar o anonimato da referida revista. Portanto, outras informações sobre política editorial, como orientações aos pareceristas ou normas para publicação, podem ser obtidas pelo email da autora: osilenecruz@bol.com.br.

4 Foram excluídos do corpus os pareceres referentes à resenha ou ensaio e também os pareceres elaborados em língua estrangeira. 


\section{Análise dos dados e discussão dos resultados}

Esta análise objetiva apresentar as avaliações dos pareceristas, com foco nas instanciações metafóricas, ou seja, de que modo os avaliadores apresentam suas críticas e sugestões metaforizadas e os desdobramentos dessas metáforas no discurso do parecerista. O Quadro 3 apresenta uma síntese das avaliações dos pareceres.

QUADRO 3: Síntese do total de avaliações nos grupos de pareceres

\begin{tabular}{|c|c|c|c|}
\hline Pareceres & Positiva & Negativa & Total \\
\hline Aprovados sem restrições (12) & $72(67 \%)$ & $36(33 \%)$ & 108 \\
\hline Aprovados com restrições (35) & $163(17 \%)$ & $803(83 \%)$ & 966 \\
\hline Reprovados (20) & $32(9 \%)$ & $332(91 \%)$ & 364 \\
\hline
\end{tabular}

Com relação ao teor das avaliações, como era de se esperar, o grupo de pareceres A, num universo de 108 avaliações, apresenta mais avaliações positivas (67\%) e os grupos de pareceres AR e R, tendo em vista as respectivas 966 e 364 avaliações, apresentam mais avaliações negativas ( $83 \%$ e $91 \%$, respectivamente).

A análise das avaliações dos grupos de pareceres separadamente revelou algumas particularidades. No grupo de pareceres A, foi possível identificar críticas e sugestões de correção em 08 deles, sendo somente 04 dentre os avaliados considerados aptos para publicação sem nenhuma restrição. Os dados revelam que as avaliações positivas são referentes, sobretudo, aos tópicos Argumentação, Contribuição, Língua e Teoria e as avaliações negativas recaem sobre os tópicos Análise e Forma, sendo que esse último tópico recebeu avaliações exclusivamente negativas nesse grupo de pareceres.

O grupo de pareceres AR foi analisado levando em consideração as avaliações nos pareceres "aceitos com modificações mínimas" (15 pareceres), e nos pareceres "aceitos com modificações substanciais" (20 pareceres). No primeiro subgrupo, as avaliações negativas recaem sobre os tópicos Língua e Argumentação e as críticas positivas destacam o tópico Contribuição. No subgrupo de pareceres aprovados 
com restrições substanciais, os pareceristas criticaram negativamente os tópicos Língua, Argumentação, Forma, Análise e Teoria e as críticas positivas enfocaram os tópicos Contribuição e Tema.

O grupo de pareceres R, como era de se esperar, recebeu um índice de avaliações negativas considerável, destacando-se os tópicos Análise, Língua, Argumentação, Teoria e Forma. Embora com índices bem discretos, o tópico Tema foi o que levou algumas avaliações positivas.

A análise nos convida a uma reflexão. No grupo de pareceres A, por exemplo, não seriam esperadas avaliações negativas, uma vez que se trata de artigos considerados aptos para publicação. No entanto, a análise mostrou, nesse universo de $33 \%$ de avaliações negativas, críticas dos pareceristas, sobretudo, no que se refere à formatação, estruturação e à análise apresentada nos artigos, interferindo na avaliação negativa de alguns tópicos, tais como Forma e Análise.

Outra questão a ser destacada refere-se ao tópico Contribuição, que é um dos requisitos exigidos pela revista $\mathrm{RL} 1$. Além de ser referenciado no grupo A, foi também indicado positivamente no grupo AR, possibilitando a interpretação de que, apesar das restrições, esses artigos podem contribuir para a área de interesse dos leitores da revista RL1. No caso do grupo R, um dos fatores para a reprovação pode estar ligado a esse tópico também. Outra questão a ser enfatizada está relacionada ao tópico Teoria, consideravelmente abordado no grupo $\mathrm{R}$, o que não ocorre com a mesma frequência nos grupos A e AR.

Com relação às instanciações metafóricas, a análise possibilitou ver que, nos pareceres de artigos aprovados (A), as avaliações são predominantemente positivas, sendo essas críticas positivas apresentadas, predominantemente, de forma congruente. Por outro lado, as avaliações negativas e as sugestões de mudança apresentam mais formas metafóricas. Vale ressaltar que, ao se tratar de um grupo de pareceres aprovados sem restrições, não seria comum a presença de crítica negativa, no entanto, ela ocorre. Vejamos o exemplo ${ }^{5}$ a seguir.

5 Por questão de comprometimento com o anonimato dos avaliadores e dos autores, alguns trechos foram suprimidos, sem comprometer o significado como um todo dos pareceres. Os pareceres foram autorizados para pesquisa e passaram pelo Comitê de Ética da instituição onde foram coletados. 
$\mathrm{O}$ artigo tem por objetivo analisar XXXXXXX [OB]. Do ponto de vista teórico o(a) proponente baseia-se sobretudo na Teoria XXXXXX [TE], mas trata a argumentação do ponto de vista da XXXX, que vincula à interdiscursividade [TE]. O corpus foi formado a partir das respostas de estudantes de um curso livre de XXXXXX, de um curso de extensão de uma universidade particular e do primeiro e do quarto anos do curso de XXXXXX de uma universidade pública federal [ME]. A análise se dá principalmente no plano da sintaxe, mas leva também em conta as ressonâncias discursivas e os efeitos de sentido [AN]. Posto isto, pode se dizer que o artigo preenche as exigências da revista $R L 1$. A contribuição mais relevante encontra-se na análise [CO] [AN]. Algumas correções/acréscimos referentes à parte formal precisam ser feitas antes da publicação [FO]: pp. 7, 8, 9, 14, 15, 16, 17 (ver no próprio texto). (A01)

Ao realizar uma proposição, por meio da metáfora interpessoal "precisam ser feitas", o parecerista suaviza o discurso, optando pela modalidade de inclinação ou obrigação (modulação), sendo outra opção possível a recorrência a um posicionamento congruente ("faça algumas correções/acréscimos...", por exemplo).

Destaca-se que, no grupo de pareceres A, as instanciações metafóricas foram realizadas, sobretudo, por elementos modais indicativos de probabilidade/ possibilidade ("parece", "pode ser", "ganharia") e por realizações em primeira pessoa ("me parece", "sugiro", "propomos"...), indicando a subjetividade do parecerista, ou por metáfora interpessoal ("seria necessário"). Seguem alguns exemplos:

"Tendo em vista que essas dificuldades metodológicas estão invariavelmente presentes nesse tipo de estudo, considero que não faz sentido solicitar alterações. Há apenas uma observação que me parece por demais ousada a partir da evidência empírica apresentada.

[...] Seria necessário haver, por exemplo, evidência de "xxxxxxx", de alternância entre "xxxxxxxx" e "xxxxxxxx", alternância ou uso concomitante de "xxxxxxx" e "xxxxxxxx", para que essa conclusão pudesse ser sustentada por dados da produção. Assim sendo, sugiro que evidências desse tipo sejam buscadas e, caso não encontradas, que a conclusão seja modalizada, ou que outro tipo de evidência seja buscada." (A02) 
Pode-se ver a avaliação predominantemente positiva no parecer A02, embora o parecerista tenha identificado problemas na metodologia do artigo, os quais são minimizados, de modo que "não faz sentido solicitar alterações". Ao mostrar uma crítica negativa, o parecerista parece minimizar o problema encontrado ("apenas uma observação"), embora ele sinalize, de maneira sutil ("me parece") que a observação do articulista é "por demais ousada". Temos nesse excerto uma crítica ao trabalho, que é apresentada sutil e cuidadosamente pelo parecerista. Ademais, o uso da metáfora interpessoal (“seria necessário haver”) suaviza o discurso e não impede a interação entre os participantes, uma vez que há proposta de mudança por meio de metáfora interpessoal e, mais adiante, por um posicionamento em $1^{\mathrm{a}}$ pessoa ("sugiro"), na forma de sugestão e não de imposição.

Outros exemplos de uso de metáfora interpessoal, amenizando a crítica ou apresentando sugestão de mudança são apresentados a seguir.

"Minha única sugestão seria que fosse feita mais uma revisão na forma do artigo, pois encontrei alguns erros na numeração e na bibliografia: [...]" (A06)

"Sugerimos apenas uma pequena revisão no processo de digitação do texto, e, para tanto, destacamos os trechos em que essa revisão é necessária [...]" (A07)

Os exemplos apresentados anteriormente mostram que o parecerista, para manter solidariedade com o interlocutor, posiciona-se utilizando metáforas interpessoais, instanciadas por posicionamento em primeira pessoa ("minha única sugestão", "sugerimos") e metáforas ideacionais por meio de nominalização ("sugestão", "revisão"). Esses recursos traduzem um tom mais polido para a avaliação, mesmo em se tratando de propostas, de demandas do parecerista, o que torna a apresentação das sugestões para correção mais sutil e menos parcial.

De acordo com Brown e Levinson (1987), estratégias de polidez como essas mostram a intenção do autor/falante em preservar sua face, de forma que as demandas sejam apresentadas, principalmente, como sugestões. Halliday (1994) também trata desse tipo de recurso, realizado por meio de metáforas interpessoais, uma vez que, ao utilizarem proposições como "pode-se dizer", "precisam ser feitas", "seria necessário haver ocorrências", "deveriam ser revistos", “caberia dizer", fica evidente que algo é pedido e/ou desejado. No entanto, esse pedido ou demanda são apresentados sutilmente, substituindo outra possível escolha, como 
"Faça isso ou aquilo".

Com relação ao grupo de pareceres de $\mathrm{AR}$, em que houve mais casos de avaliações negativas do que no grupo anterior, a análise denota um uso menor de metáforas interpessoais. Vejamos o excerto do parecer AR04, em que o parecerista apresenta avaliações negativas:

"Na nota 4, ao invés de "XXXXXXX", melhor seria "XXXXXXX" ... p. 9 Ao invés de " $X X X X X X X X X$...", melhor seria "XXXXXXX."

p.10 Na figura 2 é necessário completar a transcrição fonética, pois faltam alguns segmentos. Da mesma forma, na legenda dessa figura, ao invés de “ $X X X X X X X$ ”, pôr "XXXXXXXXXX". (AR04)

É possível observar, na proposta de mudança, por meio da metáfora interpessoal "é necessário completar", que o parecerista busca a solidariedade do interlocutor porque mostra que sua proposta está baseada na ausência de alguns segmentos.

O parecer AR11 mostra outras instanciações de crítica negativa, em que o parecerista usa instanciações metafóricas.

"Poder-se-ia alegar que ele apresenta uma novidade no estudo "xxxxxxx" (CONTR). No entanto, é preciso destacar que, de um lado, esse não era o objetivo do texto (OBJ); de outro, um elemento significativo na tradição "Xxxxxxx", enunciado pelo autor, "'xxxxxx"”, é rapidamente mencionado no corpo do trabalho, sem maiores aprofundamentos. Seria preciso examinar mais detidamente o "espaço tenso que se erige no contexto "xxxxxxx"entre o sujeito "Xxxxxxx" e a tradição "xxxxxxx" e "xxxxxxx", para que o estudo trouxesse uma contribuição significativa para a história "xxxxxxx" (CONTR). O texto está bem escrito e, quando se diz que precisa de revisão de linguagem (LING), trata-se apenas de eliminar uns poucos erros de digitação."( AR11)

Nesse exemplo, o parecerista tece a avaliação, utilizando elementos lexicais com sentido negativo, restritivo ou adversativo: "não", "no entanto", "sem", "apenas". No entanto, ocorrências metafóricas interpessoais ("poder-se-ia alegar", "é preciso destacar", "seria preciso examinar", "enunciado", "é mencionado" e "(se) diz") conferem certa moderação à avaliação negativa. As metáforas interpessoais contribuem para amenizar a opinião do parecerista ao apresentar 
críticas negativas, como por exemplo, referente ao tópico Objetivo que não foi desenvolvido a contento no trabalho apresentado. Nesse caso, outras opções para o parecerista seriam as de recorrer a uma forma congruente e monoglóssica, como "Alego", "Destaco" e "Examine".

Ao recorrer à metáfora interpessoal, "seria preciso examinar", o avaliador confere um tom mais polido ao discurso, mostrando seu ponto de vista, aparentemente insatisfeito com o tópico Análise, que não traz "contribuição significativa para a história "xxxxxxx"”. Nessa proposta, a forma congruente seria uma ordem expressa, como "Examine". Essa análise, cujo resultado é recorrente em outros pareceres do mesmo grupo, mostra a tentativa de alinhamento do parecerista com o interlocutor.

Ao recorrer a instanciações metafóricas interpessoais, o autor/falante deixa transparecer sua subjetividade. No grupo de pareceres AR, a análise mostra que a maioria das realizações foram feitas por posicionamento de primeira pessoa ("sugiro", "na minha opinião", "me parece”), denotando a intenção do parecerista em dialogar com o interlocutor. Ocorrências indicativas de probabilidade ("talvez", "poderia", "supostamente") também foram identificadas em considerável número de ocorrências, indicando uma forma de posicionamento do parecerista, por meio da qual não há total responsabilidade pelo que é dito.

Retomamos Brown e Levinson (1987), ao destacarem que as estratégias de polidez demonstram a intenção do autor/falante em preservar sua face, sendo as demandas apresentadas em forma de sugestão. Halliday (1994) também aborda estratégias realizadas por meio de metáforas interpessoais, uma vez que, ao utilizarem proposições como "pode-se dizer", "caberia dizer", e propostas como "precisam ser feitas", "seria necessário haver ocorrências", "deveriam ser revistos", tornam evidente que algo é informado, pedido e desejado, sendo apresentados de forma sutil, substituindo outra possível escolha, como, por exemplo, "É dito que" ou "Faça isso ou aquilo".

Por fim, a análise desse grupo de pareceres mostrou que as sugestões e indicações de mudança foram apresentadas de forma acolhedora, instanciadas, principalmente, por elementos modais ou metáfora interpessoal ("pode-se dizer", "precisam ser feitas", "seria necessário haver ocorrências", "deveriam ser revistos", "caberia dizer") e posicionamento do parecerista em primeira pessoa ("me parece", "sugiro", "sugerimos"). Essas escolhas léxico-gramaticais denotaram tom polido, como uma forma de evitar conflito com o interlocutor, o 
que pareceu desnecessário, uma vez que a maior parte das críticas foi positiva.

Vale lembrar que esses recursos trouxeram um tom mais polido e mais sutil à avaliação, mesmo em se tratando de propostas, ou melhor, de demandas do parecerista. Retomamos Halliday (1994), quando versa sobre realizações por meio de metáforas interpessoais, em instanciações como "pode-se dizer", "caberia dizer", "precisam ser feitas", "seria necessário haver ocorrências", "deveriam ser revistos", as quais tornam evidente que algo é informado, pedido e desejado. Ao apresentar as propostas por meio de metáforas interpessoais, o produtor textual ampliou o potencial de negociação com o interlocutor, tornando o comando ou pedido mais sutil (HALLIDAY e MATTHIESSEN, 2004, p. 632-633).

Com relação às avaliações no grupo de pareceres $\mathrm{R}$, verificamos que a maioria das críticas são apresentadas em formas congruentes, revelando que o avaliador não demonstra constrangimento em apresentar os problemas nos artigos. $\mathrm{O}$ excerto a seguir traz alguns exemplos dessas ocorrências.

"O autor assume a teoria "xxxxxxx" (cita manuais e autores dentro desse enfoque) mas a análise que o autor dá para os exemplos em (2) - especialmente em $(2 \mathrm{~d}, \mathrm{e})$ - não está de acordo com essa perspectiva teórica [Análise]. Em particular, o autor não explicita o que quer dizer com "“"xxxxxxx"” [Língua], e logo em seguida, nas notas 3 e 4 , a questão fica obscura [Língua]. Vejase: Em (2d) diz "xxxxxxx", quando há um sujeito na sentença [Análise]. Em (2e) diz que há "xxxxxxx", mas a sentença apresenta um objeto nulo e (uma categoria diferente de "xxxxxx", nesse enfoque teórico) [Análise]. A nota 3 não é explícita [Língua] e, dessa forma, contradiz o que o autor declara no texto quando afirma que "xxxxxxx" [Argumentação]. Se o autor propõe que há apagamento de complemento em (2e), por exemplo, como diz que é difícil aceitar apagamento? Ou seja, quando sabemos se é possível apagar ou não? [Argumentação] Nesse sentido, na nota 4, o autor também diz que se poderia assumir "xxxxxxx", através do grau de ligação semântica entre os argumentos e o verbo ("xxxxxxx"), o que, mais uma vez, parece contradizer o que diz acima sobre "xxxxxxx" [Argumentação]." (R02)

Esse excerto mostra que as avaliações estão relacionadas, principalmente, aos tópicos Língua e Argumentação e que as críticas ao articulista são apresentadas de forma não metafórica, sobretudo: "mas a análise [...] não está de acordo com essa perspectiva teórica"; "o autor não explicita o que quer dizer"; "[o autor] diz "xxxxxx", quando há um sujeito na sentença"; "[o autor] diz "xxxxxxx", mas a 
sentença apresenta"; "a nota 3 não é explicita e, dessa forma, contradiz o que o autor declara".

Um dado particular e surpreendente neste grupo de pareceres revela o uso de instanciações de cunho afetivo, contradizendo o tom imparcial, característica do gênero acadêmico. $O$ excerto do parecer R10, a seguir, mostra uma ocorrência de instanciação afetiva.

"Na sua apresentação da história "xxxxxxx", acredito piamente que o autor/a autora deve informar, em linhas gerais, um pouco sobre a vida e obra de "xxxxxxx", "xxxxxxx", "xxxxxxx". Lamento dizer que o texto não está amarrado ou como se diz popularmente 'redondo'." (R10)

Nesse exemplo, o parecerista tece uma crítica negativa ao tópico Língua, destacando a tessitura do texto. Essa avaliação é apresentada de forma mais acolhedora, evidente, não só pela presença do processo mental "Lamento", como também por outros enunciados que evidenciam a subjetividade do parecerista: posicionamento em primeira pessoa ("acredito") acompanhado de um elemento lexical intensificador ("piamente"), dando mais intensidade ao seu posicionamento. Vale destacar que, embora haja subjetividade e acolhimento do parecerista, a proposta de mudança é apresentada, pois o articulista "deve informar". As ocorrências de afetividade, nesse caso, serviram como um disfarce para a imposição do parecerista.

Como descrito em outro exemplo, as realizações avaliativas são sinalizadas por itens lexicais indicativos de negação, revelando ao interlocutor uma posição ou ponto de vista com o qual ele não concorda, pois sua posição é contrária à apresentada no artigo. Ao recorrer à instanciação de polaridade negativa, o parecerista assume o grau máximo de responsabilidade pelo que está avaliando. Veja-se o exemplo a seguir, extraído do parecer R02. 
“1. Embora o trabalho aborde uma questão interessante [TE], o objetivo do trabalho não está claramente expresso [OBJ], não havendo também uma articulação bem construída entre as seções [FO].

2. Observações sobre a argumentação:

A argumentação não está bem desenvolvida [AR] e, portanto, não é convincente [AR].

Já no início do texto, não há um estabelecimento claro do problema [LIN]. O autor coloca, na primeira sentença:

'Essa proposta é uma tentativa de estabelecer, com um pouco mais de precisão, a diferença entre "xxxxxxx" e "xxxxxxx"

e, mais abaixo:

"Mas tenho a intenção de mostrar que "xxxxxxx" são estabelecidos em uma "xxxxxxx", e, que, sintaticamente, a diferença entre "xxxxxxx" e "xxxxxxx" é simplesmente estrutural, ou seja, é só uma questão de posição e que não tem relação com "xxxxxxx".'

Assim, não fica claro se o texto vai estabelecer as diferenças entre " $x x x x x x x "$ e "xxxxxxx", ou se vai argumentar a favor de um mapeamento não estrito entre “xxxxxxx" e realização estrutural [LING]." (R02)

Esse excerto é constituído por avaliações sobre diversos tópicos, tais como Tema, Língua, Forma e Argumentação, as quais são reveladas, sobretudo, por orações com polaridade negativa. No entanto, o parecerista utiliza estratégias para disfarçar esse posicionamento de extrema responsabilidade ao avaliar, como pode ser visto no início do parecer, quando ocorre a única avaliação positiva relativa ao Tema do artigo, considerado interessante. A partir desse elogio, o parecerista destaca vários problemas relacionados à falta de clareza com relação ao tópico Objetivo, à falta de articulação entre as seções, afetando o tópico Forma. Além disso, utiliza enunciados de polaridade negativa para avaliar o tópico Argumentação, que não está bem desenvolvido e não é convincente. A falta de clareza ocorre também no estabelecimento do problema tratado no artigo.

O parecer R08, reproduzido na íntegra a seguir, mostra o predomínio de ocorrências típicas de avaliação negativa no grupo de pareceres R. 
"Trata-se de um artigo eminentemente descritivo. Não está claro qual a hipótese a ser investigada [OBJ]. Há também imprecisões na análise dos dados (AN). Não resulta evidente que expressões tais como "xxxxxxx" e "xxxxxxx" sejam de fato metafóricas [AN]. XXXX é uma sensação, e uma sensação pode ser descrita em termos de intensidade (forte) e dos efeitos (horrível) que ela causa. Não se discute a fundo as formas ("Xxxxxxx" ou "xxxxxxx") de se referir à XXX [AN]." (R08)

Analisando esse exemplo, observa-se o predomínio de posicionamentos realizados, principalmente, pelo item lexical "não", sinalizando avaliação de polaridade negativa sobre o trabalho apresentado, especificamente sobre a clareza da hipótese a ser estudada e sobre as evidências para os argumentos sobre metáfora, sobre a discussão de sentido literal ou metafórico de xxxx. A análise revela que o parecerista demonstra não ter interesse em dialogar com seu leitor, tornando-se monoglóssico: "Trata-se de um artigo eminentemente descritivo" e "Há também imprecisões na análise dos dados", como uma forma de reiterar a certeza sobre a avaliação, sinalizando certa verdade evidenciada pelo parecerista. A realização de teor mais sutil na avaliação ("pode ser descrita") parece amenizar o enunciado, por ser uma expressão modalizada, indicando possibilidade ou pouco comprometimento do parecerista. No entanto, a maioria das ocorrências reforça a restrição ao diálogo.

Como se pode ver nesses exemplos, instanciações metafóricas não são preponderantes nesse grupo de pareceres.

A seguir, são apresentadas as Considerações finais do artigo.

\section{Considerações finais}

Este artigo buscou mostrar instanciações metafóricas em pareceres de artigos de uma revista científica, por meio de uma análise realizada em um corpus constituído por pareceres, divididos em três grupos (A, AR, R).

Com base nos pressupostos teóricos da Linguística Sistêmico-Funcional, especificamente pelos conceitos de metáfora gramatical (HALLIDAY, 1994; HALLIDAY e MATHIESSEN, 2004), foi possível verificar que os pareceristas apresentam avaliações mais suavizadas nos pareceres A e nas sugestões de mudança, o que não seria esperado, uma vez que artigos aceitos para publicação 
sem restrições não deveriam ser alvo críticas ou sugestões de mudanças. Ainda assim, percebe-se que essas sugestões são apresentadas de forma modalizada ou metafórica.

As avaliações no grupo de pareceres AR mostram mais críticas negativas, mas os avaliadores buscam mostrar sua solidariedade ao autor do artigo, apresentando as críticas e recomendações de mudança em forma de sugestão. Esse dado mostra a intenção do parecerista em parecer alinhado com seu interlocutor, embora saiba que suas sugestões são interpretadas como indicativas de mudança e devem ser cumpridas.

O grupo de pareceres $\mathrm{R}$ mostra significativa presença de avaliações negativas, dado que é esperado, em virtude da particularidade desse grupo. O parecerista mostra os problemas e demonstra seu interesse em apresentar as críticas e as mudanças necessárias, apesar de duas incidências que chamam a atenção, pois trazem instanciações de significado afetivo.

De modo geral, a pesquisa revela um dado interessante que se refere a certa convenção de que o parecer é um gênero textual elaborado de forma imparcial, em que o autor se distancia do seu leitor e não hesita em desagradar o autor do artigo. As instanciações metafóricas revelam exatamente o oposto, pois o parecerista apresenta instanciações afetivas e subjetivas. Esse dado pode ser uma evidência questionável ao que propõe Thompson (2006), quando diz que, em discurso da área científica, realizações metafóricas são mais valorizadas, por visarem mais objetividade e em narrativas orais, há mais ocorrências de metáforas interpessoais.

A análise de metáforas interpessoais neste trabalho contribui para ratificar que a linguagem é utilizada para materializar interações, neste caso, interação entre parecerista e articulista, em que são evidentes troca de informações e de serviços. A metáfora interpessoal, vista nos pareceres analisados, revela significado de relações entre os participantes envolvidos (parecerista e autor do artigo) e o modo como o avaliador expressa sua opinião, utilizando termos para dizer o sim e o não e os graus intermediários entre o sim e o não. Nesse sentido, o estudo de metáforas gramaticais, e, mais especificamente neste trabalho, de metáforas interpessoais, mostra-se como uma ferramenta em potencial na análise discursiva, pois revela dados sobre as interações humanas e o modo como essas relações ocorrem dentro de uma perspectiva sistêmico-funcional da linguagem.

Cabe registrar uma limitação deste trabalho devido aos recortes, uma vez que a pesquisa maior contempla a análise dos pareceres, incluindo no trabalho todas as 
considerações e pesquisa baseadas a partir do Sistema de Avaliatividade (MARTIN E WHITE, 205). Entretanto, espera-se que este estudo tenha apresentado, de forma consistente, os dados que denotam instanciações metafóricas no gênero parecer de revista de divulgação científica.

\title{
Yes or No in peer reviews - a study on the interpersonal metaphor instantiations under the functional systemic perspective
}

\begin{abstract}
Recent studies reveal the importance of discursive analysis on academic texts, due to themes as well as instantiations present in this genre. This study aims at analysing peer reviews from a Linguistics scientific journal and is based on the Systemic Functional Linguistics approach (HALLIDAY, 1994; HALLIDAY \& MATTHIESSEN, 2004), especially on the interpersonal metafunction and the concept of grammatical metaphor. The corpus consists of 67 peer reviews, organized in three groups: approved articles without restrictions (A), approved articles with restrictions (AR) and rejected articles (R). Using the paradigm of qualitative research approach, the study identified thirteen topics (aboutness) discussed by referees: Abstract, Analysis, Argumentation, Bibliography, Contribution, Form, Language, Methodology, Objective, Result, Theme, Theory and Title, that were analysed under the perspective of interpersonal metaphor, with evaluations predominantly positive for group A and negative in groups AR and R. In group $\mathrm{A}$, the indications to corrections and suggestions were instantiated through interpersonal metaphor as a strategy to soften the critics. Group AR also presents occurrences of interpersonal metaphor, particularly, when the referees show the suggestions to correction, which must be followed so that the paper is published. Groups R presents negative evaluations, particularly through monoglossic instantiations, avoiding negotiation between the author and the referee. Results of this research bring contributions to studies on grammatical metaphor and on peer review genre. It may also contribute to Journal RL1, providing information to improve, even more, its prestige.
\end{abstract}

Keywords: Systemic Functional Linguistics. Grammatical metaphor. Interpersonal metaphor. Peer reviews. Academic writting. 
Referências

BARBARA, L.; MACEDO, C. M. M. de. Processos verbais em artigos acadêmicos: padrões de realização da mensagem. In: BARBARA, L.; MOYANO, E. Textos em linguagem acadêmica: explorações sistêmico-funcionais em espanhol e português. Campinas, SP: Mercado das Letras, 2011.

BERBER SARDINHA, A. P. Metáfora. São Paulo: Parábola, 2007.

BERNARDINO, C. G. O metadiscurso interpessoal em artigos acadêmicos: espaço de negociações e construção de posicionamentos. 2007. Tese (Doutorado em Linguística Aplicada) - Universidade Federal de Minas Gerais, Belo Horizonte, 2007.

BROWN, P.; LEVINSON, S. Politeness: some universals in language usage. Cambridge: Cambridge University Press, 1987.

CHIZZOTTI, A. Pesquisa em Ciências Humanas e Sociais. 3.ed. São Paulo: Cortez, 1998.

ESTRELA, C. Metodologia científica: ensino e pesquisa em odontologia. São Paulo: Artes Médicas, 2001.

FLICK, U. Introdução à pesquisa qualitativa. Tradução: Joice Elias da Costa. 3.ed. São Paulo: Artmed, 2009.

GRUSZYNSKI, A. C.; GOLIN, C.; CASTEDO, R. Produção editorial e comunicação científica: uma proposta para edição de revistas científicas. Revista da Associação Nacional dos Programas de Pós-Graduação em Comunicação, Brasília, v.11, n.2, p. 1-17, maio - ago. 2008.

HALLIDAY, M. A. K. An introduction to Functional Grammar. London: Edward Arnold, 1985.

HALLIDAY, M. A. K. An introduction to Functional Grammar. 2.ed. London: Edward Arnold, 1994.

HALLIDAY, M. A. K. Language as social semiotic: the social interpretation of language and meaning. Australia: Edward Arnold, 1978.

HOUGHTON, B. Scientific periodicals: their historical development, characteristics and control. London: The Central Press, 1975.

HOUAISS, A.; VILLAR, M. S. Dicionário Houaiss da língua portuguesa. Rio de Janeiro: Objetiva, 2001. 
LAKOFF, G.; JOHNSON, M. Metaphors we live by. Chicago: University of Chicago Press, 1980. CAMERON, L. Metaphor in educational discourse. London: Continuum, 2003.

LINS, N. F. Gêneros discursivos e o ensino de linguagem. Revista Letra Magna - Revista Eletrônica de Divulgação Científica em Língua Portuguesa, Linguística e Literatura v. 4, n. 211 6, 2007. Disponível em: <http://www. diaadiaeducacao.pr.gov.br/diaadia/diadia/arquivos/File/conteudo/artigos_teses/ LinguaEspanhola/artigos/art_neilton.pdf>. Acesso em: 04 set. 2010.

MACHADO, A. R. Revisitando o conceito de resumos. In: DIONISIO, A.P. et al. (Orgs.). Gêneros textuais \& ensino. Rio de Janeiro: Lucerna, 2002. p. 138-150.

MORAES, F. B. C. Análise comparativa das conclusões de artigos científicos das áreas de Odontologia e Linguística. In; BARBARA, L. e MOYANO, E. Textos em linguagem acadêmica: explorações sitêmico-funcionais em espanhol e portugues. Campinas: Mercado das Letras, 2011. p. 193-212.

MOTTA-ROTH, D. A construção social do gênero resenha acadêmica. In: MEURER, J. L.; MOTTA-ROTH, D. (Orgs.) Gêneros textuais. Bauru: EDUSC, 2002. p. 77-116.

PAULA, S. M. O metadiscurso em introduções de artigos científicos: uma perspectiva sistêmico-funcional. 2009. Dissertação (Mestrado em Linguística Aplicada e Estudos da Linguagem) - Pontifícia Universidade Católica de São Paulo, São Paulo, 2009.

PILAR, J. A redação de vestibular como gênero. In: MEURER, J. L.; MOTTAROTH, D. (Orgs.) Gêneros textuais. Bauru: EDUSC, 2002. p. 159-174.

SCHLENDLINDWEIN, S. L. Publique ou pereça. Boletim Informativo da SBCS. Opinião, p. 10-11, jan.-abr. 2009. Disponível em: $<$ http://sbcs.solos.ufv. $\mathrm{br} /$ solos/boletins/abertura\%20publique $\% 20$ ou $\% 20$ pere $\% \mathrm{C} 3 \% \mathrm{~A} 7 \mathrm{a} . \mathrm{pdf}>$. Acesso em: 22 mar 2010. (2009).

VIAN JR., O.; IKEDA, S. N. O ensino do gênero resenha pela abordagem sistêmico-funcional na formação de professores. Linguagem \& Ensino. Pelotas, v.12, n.1, p.13-32, 2009.

VIVAN. E. G. S. Principais usos de processos verbais e metáforas interpessoais em artigos de Linguística Aplicada. 2010. Tese (Doutorado em Linguística Aplicada e Estudos da Linguagem) - Pontifícia Universidade Católica de São Paulo, São Paulo, 2010. 
VOLPATO, G. L.; FREITAS, E.G. Desafios na publicação científica. Pesquisa Odontológica Brasileira. São Paulo, v. 17, n. 1, p. 49-56, 2003. Disponível em: $<$ http://www.scielo.br/pdf/pob/v17s1/a08v17s1.pdf $>$. Acesso em: 10 maio 2010.

THOMPSON, G. Introducing Funcional Grammar. London: Edward Arnold, 1996.

Submetido: 04/02/2016

Aceite: 06/09/2016 